\title{
RADIOCARBON CALIBRATION CURVE VARIATIONS AND THEIR IMPLICATIONS FOR THE INTERPRETATION OF NEW ZEALAND PREHISTORY
}

\author{
B. G. MCFADGEN, ${ }^{1}$ F. B. KNOX ${ }^{2}$ and T. R. L. COLE ${ }^{3}$
}

\begin{abstract}
The shape of a distribution of calibrated ${ }^{14} \mathrm{C}$ dates displays spurious peaks and troughs, brought about by changes in the slope of the calibration curve interacting with the spreading effect of the stochastic distribution of counting errors. The distortion results in a positive correlation between the numbers of dates per calendar year and the slopes of the calibration curves, for assemblages of archaeological dates from such widely separated areas as British Columbia, South Australia and New Zealand. The distortion also increases the possibility of date reversals, and increases the overall spread of calibrated ${ }^{14} \mathrm{C}$ dates. After taking into account this systematic distortion and inbuilt age of charcoal and wood samples, we estimate dates for the initial settlement and first appearance of fortifications, and infer a likely trend of population growth for prehistoric New Zealand.
\end{abstract}

\section{INTRODUCTION}

More than $800{ }^{14} \mathrm{C}$ dates of terrestrial and marine samples exist for New Zealand prehistory, which is only ca. $500 \mathrm{yr}$ long (Anderson 1991). This gives an average of $>1.5$ dates per year. ${ }^{14} \mathrm{C}$ dates are important for determining New Zealand settlement, and for dating events such as the extinction of the moa (a very large, extinct, flightless bird of New Zealand) and the first appearance of fortifications.

Calibration of ${ }^{14} \mathrm{C}$ dates using accepted procedures (e.g., Stuiver and Reimer 1993) produces strange results, which have led to fallacious inferences about the chronology of New Zealand prehistory. The distribution of calibrated shell dates is shorter than that of calibrated dates on charcoal and wood. The shell curve has a short "tail" with few dates older than $700 \mathrm{cal} \mathrm{BP}$, and its peaks and troughs are located at different calendar dates than for charcoal and wood (Fig. 1B, C). For the shell dates, peaks correspond to steep slopes of the marine calibration curve, and troughs, to gentle slopes (Fig. 1A, C). For charcoal and wood, peaks correspond to steep slopes of the terrestrial calibration curve; troughs correspond to the "wiggles" (Fig. 1A, B). For charcoal and wood dates, the relation between peaks, troughs and calibration curve wiggles appears to be universal for the Pacific, and also occurs for South Australia and coastal British Columbia. Here we discuss these peculiarities of ${ }^{14} \mathrm{C}$ date calibration in the context of New Zealand prehistory.

\section{METHODS}

We use the 1993 marine and terrestrial calibration curves (Stuiver and Braziunas 1993; Stuiver and Pearson 1993). In each case, we fit a cubic spline to pass through each data point and provide pairs of ${ }^{14} \mathrm{C} / \mathrm{calendar}$ dates for each calendar year back to $1400 \mathrm{cal} \mathrm{BP}$. Characteristic wiggles identify sections of the curve where more than one calendar date exists for each ${ }^{14} \mathrm{C}$ date. We call these sections ambiguous regions (Fig. 2). One can find the boundary of an ambiguous region by projecting from a wiggle maximum a horizontal line forward in calendar time to intercept the calibration curve (Fig. 2: f), and from a wiggle minimum backward in time to intercept the calibration curve (Fig. 2: e). Boundary values in calendar and ${ }^{14} \mathrm{C}$ years are read off the appropriate calibration curve axis. The "slope" of an ambiguous region is represented by a line between the two points where the horizontal lines intercept the calibration curve.

\footnotetext{
${ }^{1}$ Conservation Sciences Centre, Department of Conservation, P.O. Box 10420, Wellington, New Zealand

2900 Ohariu Valley Road, R.D., Johnsonville, New Zealand

${ }^{3}$ Department of Labour, P. O. Box 3705, Wellington, New Zealand
} 

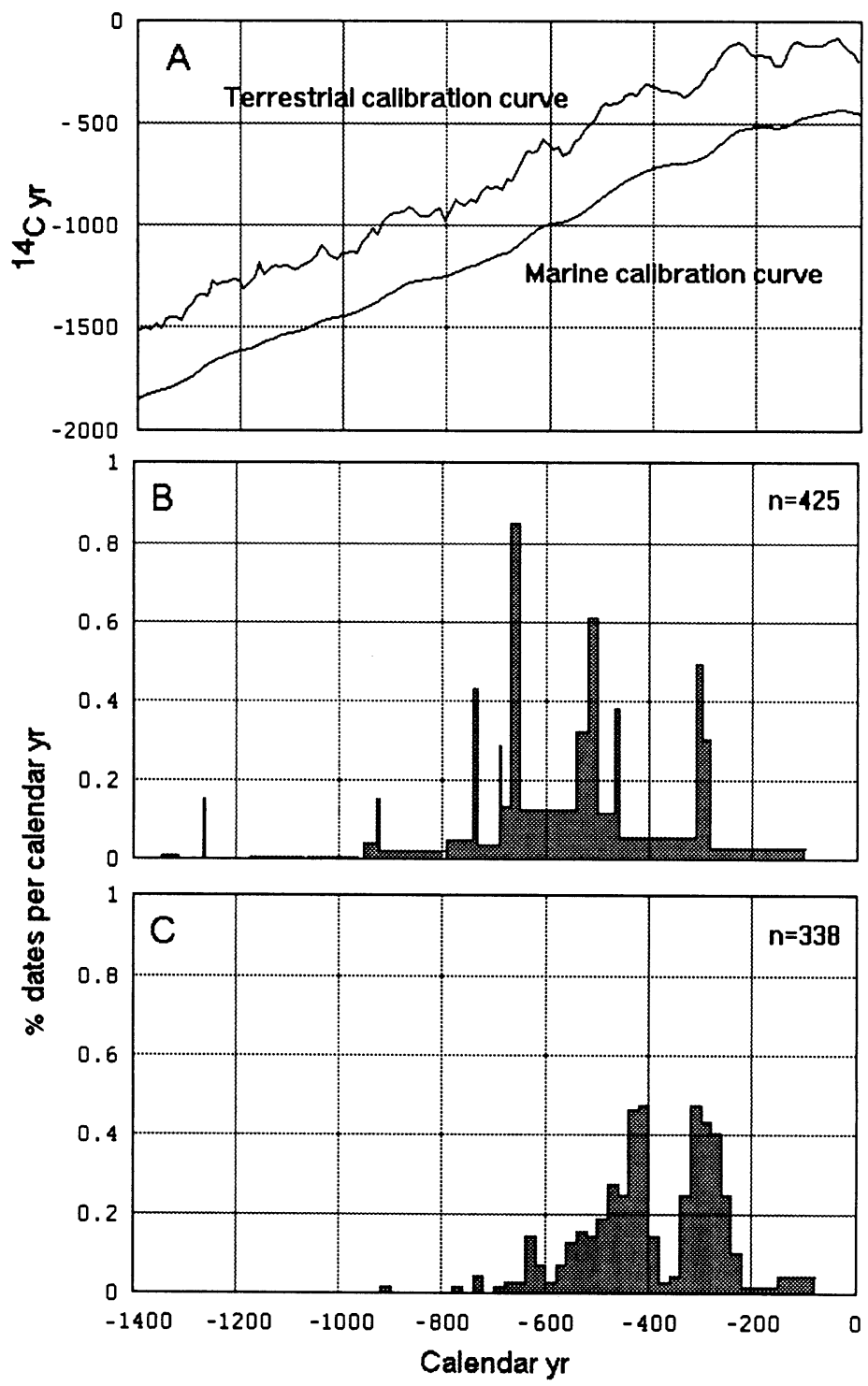

Fig. 1. Graphs of calibrated dates for New Zealand prehistory compared with the terrestrial and marine calibration curves. A. Calibration curve data from Stuiver and Pearson (1993) (terrestrial) and Stuiver and Braziunas (1993) (marine); B. wood and charcoal dates; C. marine shell dates. Note that calendar and ${ }^{14} \mathrm{C}$ years before present are shown as negative, with 0 representing $A D$ 1950. $n=$ the number of ${ }^{14} \mathrm{C}$ dates represented by each graph. For the wood and charcoal terrestrial dates, $n=$ the number of dates between -121.92 and $-1581.55{ }^{14} \mathrm{C}$ years $(-100$ and -1500 calendar years, respectively), and for the marine shell dates, between -452.01 and $-1921.2{ }^{14} \mathrm{C}$ years ( -78 and -1500 calendar years, respectively). For explanation of class widths, see text.

We do not apply a correction to the terrestrial calibration curve to compensate for the apparent offset of ${ }^{14} \mathrm{C}$ between the northern and southern hemispheres (Vogel et al. 1993). We find the data of Vogel et al. (1993) unconvincing because they indicate an inverse variation of ${ }^{14} \mathrm{C}$ between the two hemi- 


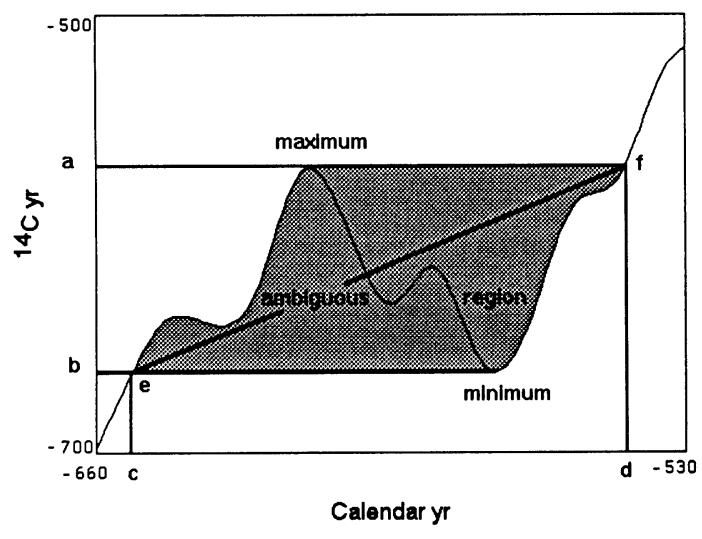

Fig. 2. Definition of an ambiguous region (四). $a, b=$ ambiguous region boundaries on the ${ }^{14} \mathrm{C}$ axis; $\mathrm{c}, \mathrm{d}=$ ambiguous region boundaries on the calendar axis. The slope of an ambiguous region is the slope of the line joining $e$ and $f$.

spheres. Recent measurement of the ${ }^{14} \mathrm{C}$ content of New Zealand tree rings suggests that the southern hemisphere offset is either very small or non-existent (Dr. R. G. Sparks, personal communication 1994). The peculiarities of ${ }^{14} \mathrm{C}$ calibration discussed here are present whether or not the $40-\mathrm{yr}$ offset is applied.

Archaeological dates were determined at the Institute of Geological and Nuclear Sciences, Lower Hutt, prior to May 1992. All results since 1988, including accelerator mass spectrometry (AMS) dates, are in strict accordance with the recommendations of Stuiver and Polach (1977). Measurements made before 1988 have been recalculated to meet the same conventions. We have included published ${ }^{14} \mathrm{C}$ dates from other laboratories whenever available. All our dates are on charcoal, wood, moa bone or marine shell stratigraphically contemporary with evidence of human activity. We include estuarine samples except for mudsnail shells (Amphibola crenata), as these can have $\delta^{13} \mathrm{C}$ values suggesting the ingestion of terrestrial carbon. Marine shell dates are calibrated using $\Delta R=$ -31 (McFadgen and Manning 1990).

In our graphs of date distributions, bar heights represent the percentage of dates per calendar year for each class. The dates are calibrated conventional ${ }^{14} \mathrm{C}$ ages considered as "point" dates without regard for their standard errors. ${ }^{14} \mathrm{C}$ dates in ambiguous regions have multiple intercepts on the calibration curve and correspond to more than one calendar date. The number of ${ }^{14} \mathrm{C}$ dates in an ambiguous region must match the number of calendar dates. Thus, to avoid the dilemma of how to allocate one ${ }^{14} \mathrm{C}$ date among multiple calendar date possibilities (Stuiver and Reimer 1989), we treat each ambiguous region as a single class. (How to determine the distribution of dates within an ambiguous region is the subject of a future paper.) For parts of the calibration curve between ambiguous regions, a 20 -yr class is adopted where the interval is sufficiently large. For shell date graphs, 20-yr classes are between 220 and $1400 \mathrm{cal} \mathrm{BP}$. For charcoal and wood, and moa bone graphs, 20-yr classes are between 285 and $312 \mathrm{cal} \mathrm{BP}$, and 501 and $544 \mathrm{cal} \mathrm{BP}$, respectively.

\section{EFFECTS OF INBUILT AGE AND CALIBRATION CURVE STOCHASTIC DISTORTION ON DISTRIBUTIONS OF CALIBRATED DATES}

Two factors contribute to the differences between the two distributions of calibrated dates: inbuilt age (McFadgen 1982), and the "calibration stochastic distortion (CSD) effect". Inbuilt age is the difference in age between the death of the sample and the archaeological event dated. For wood, it is the combination of growth age (the age of old wood in a tree) and storage age (the time the tree was lying around before it was used). The CSD effect is the systematic increase or depletion of the num- 
ber of calibrated dates on the calendar scale, related to the slope of the calibration curve. We show below that this occurs because the change in the slope of the calibration curve interacts with the spreading effect of the stochastic distribution of counting errors.

Charcoal and wood samples collected before the mid-to-late 1970 s were rarely identified by species and little effort was made to collect twigs. Consequently, many charcoal and wood samples have an unknown and possibly large inbuilt age (McFadgen 1982). Samples collected since the mid-1970s have been routinely identified. Short-lived species are classed here as those with a potential life span of $<100 \mathrm{yr}$ (i.e., ca. 2 standard errors of an average ${ }^{14} \mathrm{C}$ date), and long-lived species as those with a potential life span of $>100 \mathrm{yr}$ (Table 1 ).

TABLE 1. Life Expectancy of Plant Species Used for ${ }^{14} \mathrm{C}$ Dating in New Zealand*

\begin{tabular}{|c|c|c|}
\hline Short $(<100 \mathrm{yr})$ & Medium $(100-300 \mathrm{yr})$ & Long $(>300 \mathrm{yr})$ \\
\hline $\begin{array}{l}\text { Aristotelia serrata } \\
\text { Brachyglottis sp. } \\
\text { Carmichaelia sp. } \\
\text { Carpodetus serratus } \ddagger \\
\text { Cassinia } \text { sp. } \\
\text { Coprosma sp. } \\
\text { Coriaria sp. } \\
\text { Corokia macrocarpa } \\
\text { Geniostoma rupestre } \\
\text { Hebe sp. } \\
\text { Hedycarya arborea } \ddagger \\
\text { Leptospermum scoparium } \ddagger \\
\text { Leucopogon fusciculatus } \\
\text { Lophomyrtus obcordata } \ddagger \\
\text { Macropiper excelsus } \\
\text { Melicytus ramiflorus } \ddagger \\
\text { Melicytus sp. } \ddagger \\
\text { Myrsine australis } \ddagger \\
\text { Myrsine sp. } \ddagger \\
\text { Olearia rani } \ddagger \\
\text { Pseudopanax arboreus } \ddagger \\
\text { Pseudopanax crassifolius } \ddagger \\
\text { Pseudowintera } \text { sp. } \\
\text { Pteridium esculentum } \\
\text { Schefflera digitata } \\
\text { Tree fern }\end{array}$ & $\begin{array}{l}\text { Ackama rosifolia } \dagger \\
\text { Alectryon excelsus } \\
\text { Beilschmiedia sp. } \ddagger \\
\text { Cordyline australis } \\
\text { Corynocarpus laevigatus } \\
\text { Discaria toumatou } \\
\text { Dysoxylum spectibile } \\
\text { Hoheria sp. } \dagger \\
\text { Knightia excelsa } \\
\text { Kunzea ericoides } \\
\text { Myrsine divaricata } \dagger \\
\text { Myoporum laetum } \\
\text { Nestigis sp. } \ddagger \\
\text { Olearia sp. } \\
\text { Pseudopanax sp. } \dagger \\
\text { Paratropis microphylla } \\
\text { Pittosporum eugenoides } \\
\text { Pittosporum tenuifolium } \dagger \\
\text { Plagianthus sp. } \\
\text { Sophora microphylla } \\
\text { Sophora sp. } \\
\text { Weinmannia sp. }\end{array}$ & $\begin{array}{l}\text { Agathis australis } \\
\text { Dacrydium cupressinum } \\
\text { Halocarpus kirkii } \\
\text { Lagarostrobus colensoi } \dagger \\
\text { Laurelia novaezelandia } \dagger \\
\text { Libocedrus bidwillii } \dagger \\
\text { Metrosideros } \text { sp. } \\
\text { Nothofagus } \text { sp. } \dagger \\
\text { Phyllocladus } \mathrm{sp} . \\
\text { Podocarpus totara } \\
\text { Prumnopitys spicatus } \\
\text { Vitex lucens } \dagger\end{array}$ \\
\hline
\end{tabular}

*Data provided by Dr. Philip Simpson, Botanist, Science and Research Division, Department of Conservation. †Life span can be much shorter than designated years.

$\ddagger$ Life span can be longer than designated years.

The distribution curve of dates on short-lived species has far fewer dates $>700$ cal BP than the longlived species (Fig. 3). The few short-lived species $>700$ cal BP are from Central Otago, where dry conditions enhance the survival of dead trees and shrubs. Excluding the long-lived species, the spread of calibrated dates on identified charcoal and wood concurs with the shell dates, and gives an initial estimated date for human settlement of New Zealand of $c a$. 700-800 cal BP. 


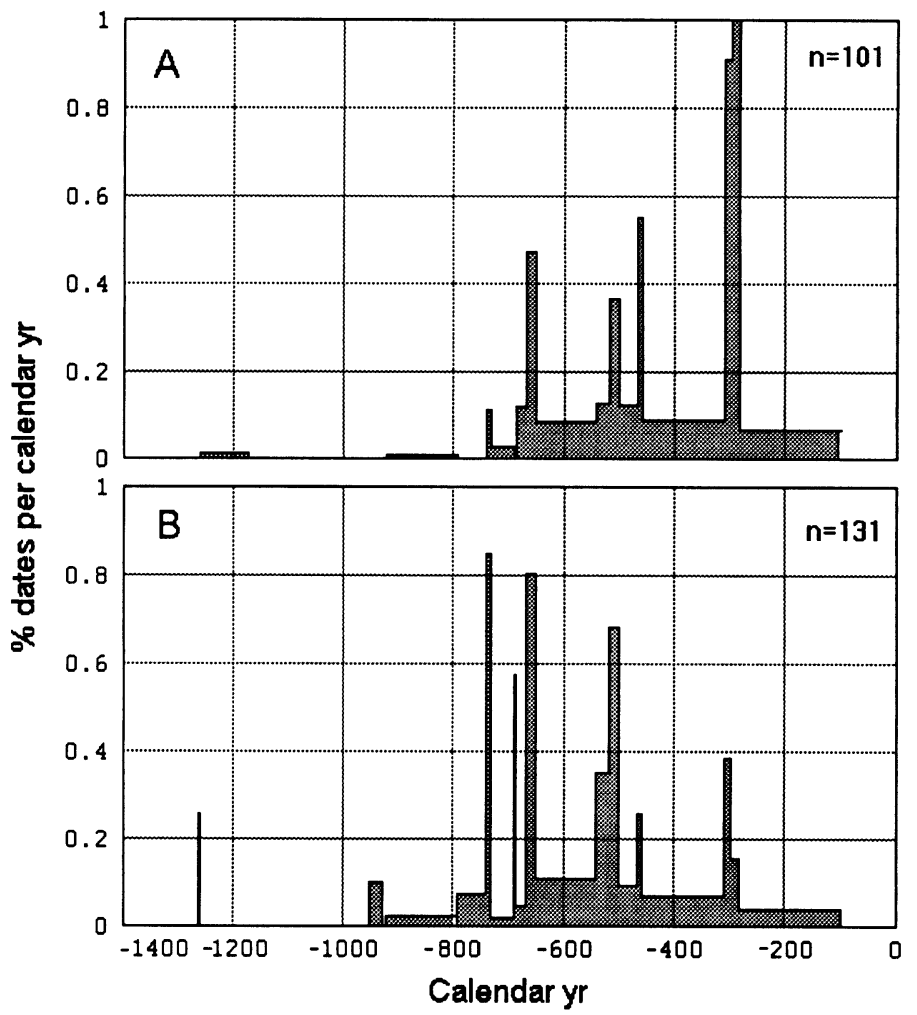

Fig. 3. Graphs of calibrated dates for New Zealand prehistory determined on short-lived (A) and long-lived (B) plant species. Note the far fewer dates on short-lived species older than $700 \mathrm{cal} \mathrm{BP}$, and the contrast in the trend of peak heights with decreasing age.

The trend of peak heights of the calibrated shell date graph and the corresponding trend of peak heights for all the charcoal and wood dates do not agree. The trend of shell peak heights (Fig. 1) fits better with the trend of short-lived charcoal and wood peak heights (Fig. 3). Inbuilt age thus appears to account for the different trend in peak height between the shells and the total set of charcoal and wood dates. The earliest major peak of the calibrated shell dates ( $c a .420 \mathrm{cal} \mathrm{BP})$ is later than the earliest major peak of the total set of charcoal and wood dates (ca. $660 \mathrm{cal} \mathrm{BP,} \mathrm{Fig.} \mathrm{1).} \mathrm{It} \mathrm{will} \mathrm{become}$ apparent, below, that the displacement of the earliest major shell peak compared with the earliest major charcoal and wood peak is due to the CSD effect.

The effects of calibration stochastic distortion on ${ }^{14} \mathrm{C}$ date calibration are well known (e.g., Stuiver and Reimer 1989), and various methods of dealing with them have been proposed (e.g., Geyh 1980; Stolk, Hogervorst and Berendsen 1989; Stuiver and Reimer 1989). However, these methods are local in that they correct isolated, individual dates or histogram classes. Our analysis of the CSD effect indicates that a global approach is necessary. All dates occurring over a ${ }^{14} \mathrm{C}$ time range equal to at least 4-6 times the counting error (standard deviation) of a typical date need to be corrected as a group. The correction procedure, borrowed from signal processing, will be a deconvolution of the measured ${ }^{14} \mathrm{C}$ distribution from the counting statistics to give the true ${ }^{14} \mathrm{C}$ distribution, which may then be mapped through the calibration curve in the usual way to give a calendar distribution substantially free of CSD effects. 
The CSD effect depletes the numbers of dates per calendar year in those parts of the calendar time scale which correspond to gentle slopes of the calibration curve or to wiggles, and increases the numbers of dates where the slopes are steep (Fig. 1). The effect is not due to the use of histograms to depict date distributions. It makes little difference whether point dates are used for the graphs, or whether standard errors are included and summed probabilities used for the graphs.

Depletion is most striking within the boundaries of the ambiguous regions of the terrestrial calibration curve, and less so within the boundaries of the flatter regions of the marine calibration curve. The effect is responsible for the narrow peaks and wide troughs of the charcoal and wood distribution, but because the flatter parts of the marine calibration curve cover fewer calendar years than the ambiguous regions of the terrestrial curve, the peaks of the shell distribution are wider and the troughs narrower. The peaks and troughs present in the New Zealand charcoal and wood distribution are matched (Fig. 4) in date assemblages of similar age on charcoals from South Australia (Bird and Frankel 1991) and British Columbia (Richards and Rosseau 1987). In all three locations, the slope of the calibration curve and the numbers of dates per calendar year within and between the ambiguous regions show a very significant positive correlation (Fig. 5). The New Zealand shell dates (Fig. 5) show a similar correlation.

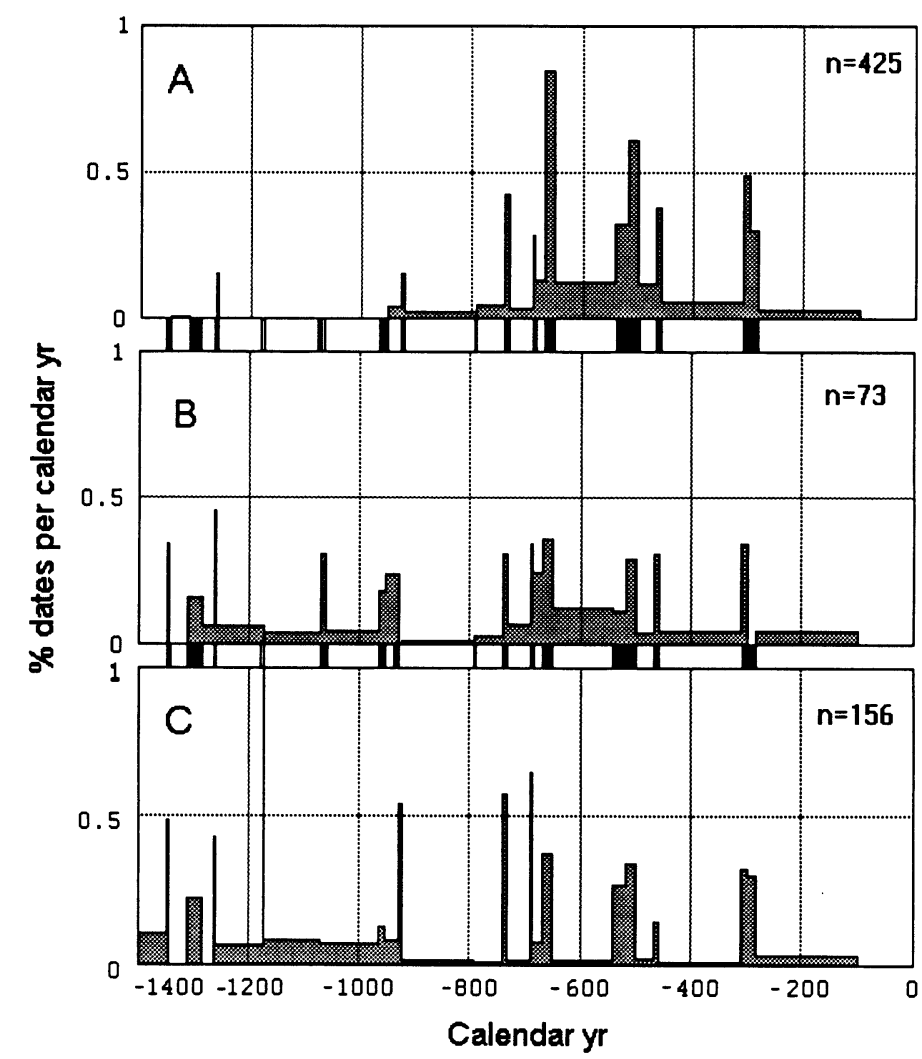

Fig. 4. Graphs of calibrated dates on charcoal and wood for New Zealand prehistory (A) compared with graphs of calibrated dates on charcoal for South Australian (B) and British Columbian (C) prehistory. Note the correspondence between non-ambiguous regions $(\square)$ and peaks of the graphs. 

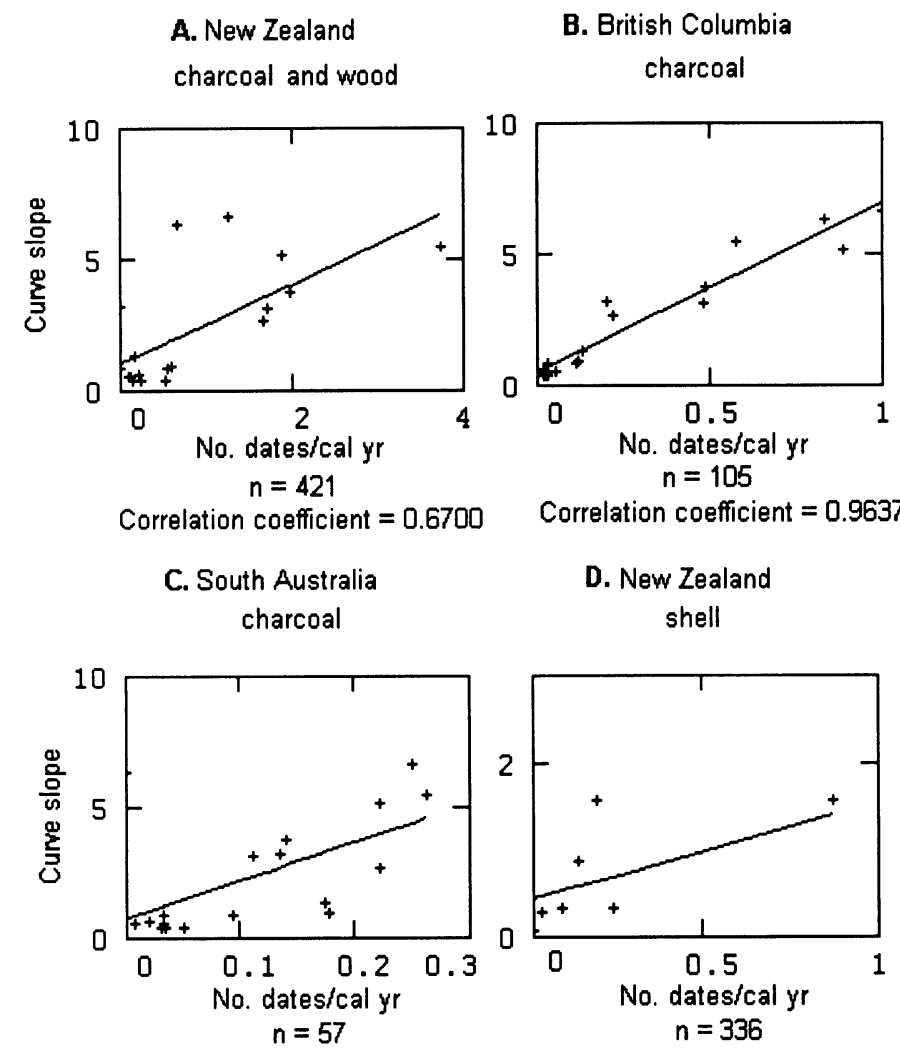

D. New Zealand shell

Correlation coefficient $=0.6013$

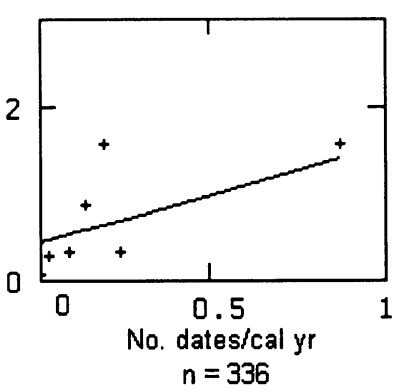

Correlation coefficient $=0.7254$

Fig. 5. Linear correlation of the numbers of dates per calendar year and the slope of the calibration curve within and between ambiguous regions for the period 100 $1062 \mathrm{cal} \mathrm{BP}$ (charcoal and wood) and 0-640 cal BP (shells). Significance of correlation coefficient measured using test statistic

$$
t=\left(r(n-2)^{0.5}\right) /\left(\left(1-r^{2}\right)^{0.5}\right)
$$

(Snedecor and Cochran 1967), where $r=$ correlation coefficient and $n=$ number of classes. d.f. $=n-2$. Correlation coefficient is highly significant in all cases: $A . t=$ 4.12, $\mathrm{P}<0.001 ; \mathrm{B} . \mathrm{t}=20.86, \mathrm{P}<0.001 ; \mathrm{C} . \mathrm{t}=3.93, \mathrm{P}<0.005 ; \mathrm{D} . \mathrm{t}=3.39, \mathrm{P}<0.025$.

The changes in the numbers of dates per calendar year between ambiguous and non-ambiguous regions could correspond to real changes in human activity in the past, correlation with the slope of the calibration curve being a common response to a factor such as climate. However, this apparent common response, of widely different cultures in different environments, to the geophysical phenomena responsible for variation in the calibration curve, makes us doubtful that this is a true cultural response. An alternative explanation of the CSD effect is that it is a construct of the interaction between changing calibration curve slope and spreading of ${ }^{14} \mathrm{C}$ dates because of counting statistics. The CSD effect is significant when the counting errors of individual ${ }^{14} \mathrm{C}$ dates are comparable with, or greater than, the time intervals over which appreciable changes in slope of the calibration curve occur. Figure 6 illustrates how the effect occurs.

Let line A represent a uniform true calendar date distribution. On mapping through the calibration curve, $\mathrm{A}$ becomes the line $\mathrm{B}$, the true ${ }^{14} \mathrm{C}$ date distribution. However, $\mathrm{B}$ is statistically spread by counting errors to become line $\mathrm{B}^{\prime}$, the observed ${ }^{14} \mathrm{C}$ date distribution. When $\mathrm{B}^{\prime}$ is mapped back 


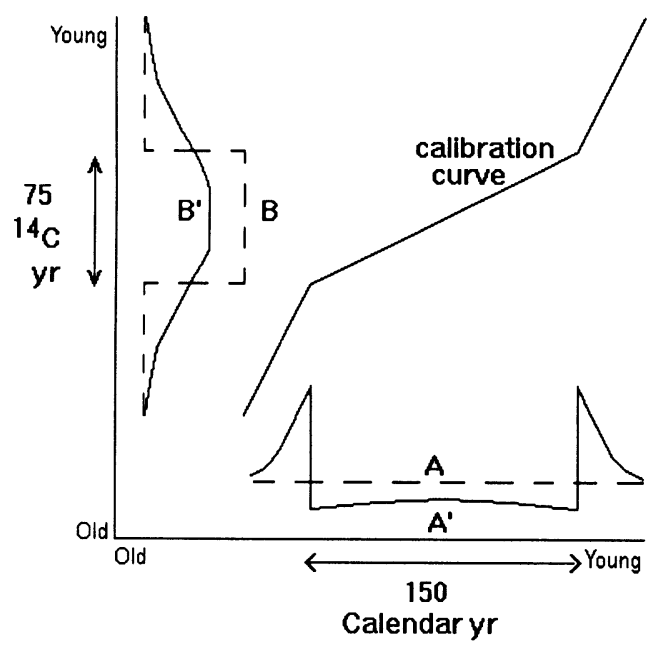

Fig. 6. Illustration of the CSD effect. A distribution of true calendar dates A (- - -) maps into a corresponding distribution of true ${ }^{14} \mathrm{C}$ dates $\mathrm{B}(--)$. The observed ${ }^{14} \mathrm{C}$ distribution $\mathrm{B}^{\prime}(-)$ is the dates in $\mathrm{B}$ after their spread by counting errors (standard deviation $=50 \mathrm{yr}$ ), and maps back into $\mathrm{A}^{\prime}(-)$, the resulting apparent calendar distribution.

through the calibration curve, it gives $\mathrm{A}^{\prime}$, the apparent calendar date distribution, which differs systematically from $\mathrm{A}$, the true distribution.

The effect is most marked around the ambiguous regions, because that is where changes in slope of the calibration curve are greatest. Distances between the beginnings and ends of ambiguous regions on the ${ }^{14} \mathrm{C}$ scale are between 6.5 and $91 \mathrm{yr}$ (Table 2), less than twice the average standard error of archaeological ${ }^{14} \mathrm{C}$ dates. Thus, counting statistics spread the dates into those parts of the curve with the steepest slopes, with a high probability of a measured ${ }^{14} \mathrm{C}$ age falling outside an ambiguous region.

Figure 7 shows a true ${ }^{14} \mathrm{C}$ date centered on an ambiguous region. The bell-shaped curve is the statistical distribution of errors of a measured ${ }^{14} \mathrm{C}$ date estimating the true ${ }^{14} \mathrm{C}$ date. The width of the ambiguous region on the ${ }^{14} \mathrm{C}$ axis is shown as equal to twice the standard error of the measured date. The probability of the measured date falling outside the ambiguous region is indicated by the unshaded portion of the bell-shaped curve and is $c a$. 0.33 . In reality, for the last $1500 \mathrm{yr}$, the width of all ambiguous regions is $<2$ average standard errors, and for over half of the ambiguous regions, it is $<1$ average standard error. Only between 544 and 652 cal BP is there a substantially better than even chance of a measured ${ }^{14} \mathrm{C}$ date falling within an ambiguous region of the terrestrial curve when the true ${ }^{14} \mathrm{C}$ date is centered in the region. This chance is reduced if the true date is off-center of an ambiguous region.

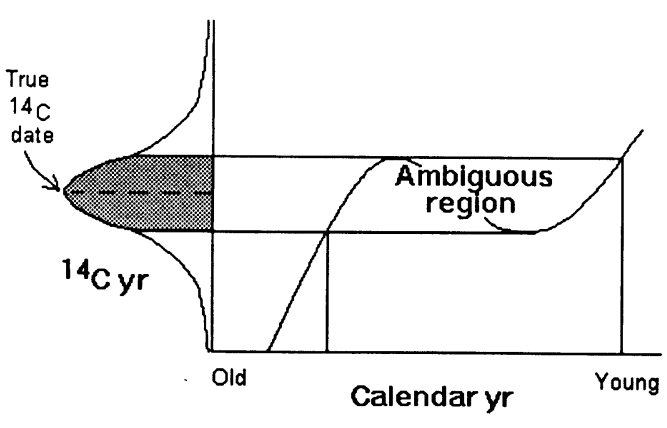

Fig. 7. Diagram to illustrate how the counting statistics of a ${ }^{14} \mathrm{C}$ date affects the probability that the date will fall outside an ambiguous region. The bell-shaped curve represents the statistical distribution of a true ${ }^{14} \mathrm{C}$ date centered on an ambiguous region that has a width in ${ }^{14} \mathrm{C}$ years equal to twice the standard error of a measured date. The unshaded portion of the curve represents the probability that the measured date falls outside the ambiguous region (0.33). 
TABLE 2. Calendar and ${ }^{14} \mathrm{C}$ age boundaries and durations of ambiguous (A) and non-ambiguous $(\mathrm{N})$ regions of the terrestrial calibration curve. Note that, with one exception (929-952 cal BP), the slope of the calibration curve across ambiguous regions is $<45^{\circ}(<1.0000)$, and across non-ambiguous regions, $>45^{\circ}(>1.0000)$.

\begin{tabular}{|c|c|c|c|c|c|}
\hline $\begin{array}{c}\text { Calendar } \\
\text { age } \\
\text { (yr BP) }\end{array}$ & $\begin{array}{c}{ }^{14} \mathrm{C} \text { age } \\
\text { (yr BP) }\end{array}$ & $\begin{array}{c}\text { Region } \\
\text { duration } \\
\text { (calendar yr) }\end{array}$ & $\begin{array}{c}\text { Region } \\
\text { duration } \\
\left({ }^{14} \mathrm{C} y r\right)\end{array}$ & $\begin{array}{l}\text { Slope of } \\
\text { region } \\
\text { (tangent) }\end{array}$ & Region \\
\hline 0 & 0 & -- & -- & -- & -- \\
\hline 285 & 227 & 285 & 227 & 0.7965 & A \\
\hline 300 & 269.47 & 15 & 42.47 & 2.8313 & $\mathrm{~N}$ \\
\hline 312 & 312.26 & 12 & 42.79 & 3.5658 & $\mathrm{~N}$ \\
\hline 459 & 373.76 & 147 & 61.5 & 0.4184 & A \\
\hline 468 & 397.47 & 9 & 23.71 & 2.6344 & $\mathrm{~N}$ \\
\hline 501 & 410.37 & 33 & 12.9 & 0.3909 & A \\
\hline 520 & 501.34 & 19 & 90.97 & 4.7879 & $\mathrm{~N}$ \\
\hline 544 & 572.59 & 24 & 71.25 & 2.9688 & $\mathrm{~N}$ \\
\hline 652 & 662.97 & 108 & 90.38 & 0.8369 & A \\
\hline 671 & 766.64 & 19 & 103.67 & 5.4563 & $\mathrm{~N}$ \\
\hline 688 & 781.97 & 19 & 15.33 & 0.8068 & A \\
\hline 692 & 808.53 & 4 & 26.56 & 6.64 & $\mathrm{~N}$ \\
\hline 732 & 824.54 & 40 & 16.01 & 0.4003 & A \\
\hline 741 & 871.23 & 9 & 46.69 & 5.1878 & $\mathrm{~N}$ \\
\hline 794 & 906.12 & 55 & 34.89 & 0.6344 & A \\
\hline 794 & 906.12 & 0 & 0 & 0 & $\mathrm{~N}$ \\
\hline 923 & 976.23 & 129 & 70.11 & 0.5435 & A \\
\hline 929 & 1014.01 & 6 & 37.78 & 6.2967 & $\mathrm{~N}$ \\
\hline 952 & 1044.79 & 23 & 30.78 & 1.3383 & A \\
\hline 967 & 1092.3 & 15 & 47.51 & 3.1673 & $\mathrm{~N}$ \\
\hline 1062 & 1171.08 & 95 & 78.78 & 0.8293 & A \\
\hline 1071 & 1182.32 & 9 & 11.24 & 1.2489 & $\mathrm{~N}$ \\
\hline 1174 & 1252.49 & 103 & 70.17 & 0.6813 & A \\
\hline 1175 & 1261 & 1 & 8.51 & 8.51 & $\mathrm{~N}$ \\
\hline 1261 & 1313.96 & 86 & 52.96 & 0.6158 & A \\
\hline 1264 & 1339.1 & 3 & 25.14 & 8.38 & $\mathrm{~N}$ \\
\hline 1286 & 1353.14 & 22 & 14.04 & 0.6382 & A \\
\hline 1312 & 1456.11 & 26 & 102.97 & 3.9604 & $\mathbf{N}$ \\
\hline 1346 & 1468.79 & 34 & 12.68 & 0.3729 & A \\
\hline 1350 & 1488.63 & 4 & 19.84 & 4.96 & $\mathrm{~N}$ \\
\hline 1406 & 1515.31 & 56 & 26.68 & 0.4764 & A \\
\hline 1415 & 1575 & 9 & 59.69 & 6.6322 & $\mathrm{~N}$ \\
\hline 1500 & 1581.55 & 85 & 6.55 & 0.0771 & A \\
\hline
\end{tabular}

The CSD effect is robust, illustrated by the calibration of a simulated set of ${ }^{14} \mathrm{C}$ dates derived from a uniform distribution of calendar dates. Figure 8 shows a typical result. The simulated dates are for every calendar year between 100 and $700 \mathrm{cal}$ BP. The true ${ }^{14} \mathrm{C}$ date corresponding to each calendar year is assigned a standard error of $50 \mathrm{yr}$, which is close to the average for New Zealand dates on charcoal and wood. The true ${ }^{14} \mathrm{C}$ dates and their assigned standard errors randomly generate the simulated ${ }^{14} \mathrm{C}$ dates. The resulting graph of calibrated dates closely resembles that of the archaeological dates; the outcome of repeated simulations differs little until standard errors reduce to $<c a$. $20 \mathrm{yr}$. 


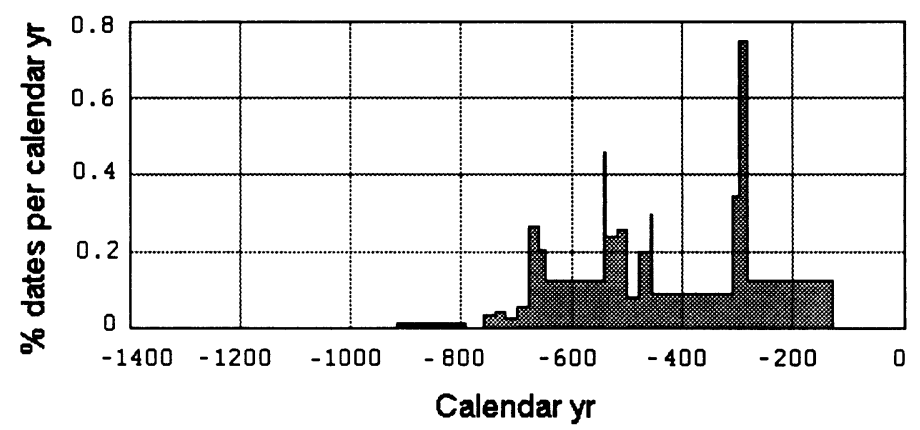

Fig. 8. Calibrated simulated ${ }^{14} \mathrm{C}$ dates, derived from a uniform distribution of calendar dates, show the production of peaks and troughs resembling the histogram of New Zealand dates on charcoal and wood

We do not observe significant change in the outcome when the distribution of dates in calendar time is non-uniform and weighted more than three times in favor of the ambiguous regions.

The simulation shows a tail to the distribution of calibrated dates, which extends back beyond 900 cal BP (Fig. 8), and is due entirely to the spreading effect of the standard errors. The tail is present in some simulations and absent in others. It indicates that the true beginning of a distribution of calibrated dates is likely to be younger than its histogram shows. The slight tail to the shell distribution, between 700 and $900 \mathrm{cal} \mathrm{BP}$ (Fig. 1), is almost certainly statistical in origin.

\section{IMPLICATIONS OF INBUILT AGE AND THE CSD EFFECT FOR NEW ZEALAND PREHISTORY}

The CSD effect makes it very difficult to determine the true calendar distribution of dates. Many of the peaks and troughs in both the charcoal and wood and the shell distributions are likely to be a function of the calibration curve. In the archaeological dates used here, the first high peak of the charcoal and wood distribution is unmatched in the shell distribution, which has a much smaller initial peak. Comparison with the distribution of short-lived charcoal and wood dates (Fig. 3) suggests a high inbuilt age component in the early charcoal dates. The true distribution of charcoal and wood dates in calendar time is probably closer to the distribution of shell dates.

The shell distribution begins $c a$. $900 \mathrm{cal}$ BP. It increases to a maximum $c a .400 \mathrm{cal} \mathrm{BP}$, drops into a marked trough $c a$. $350 \mathrm{cal} \mathrm{BP}$, increases to a peak $c a .300 \mathrm{cal} \mathrm{BP}$, and then declines after $c a .250 \mathrm{cal}$ BP. After making allowance for the CSD effect, which we show above causes peaks, troughs and spreading, the distribution provides a plausible visual representation of the likely trend of population growth in prehistoric New Zealand, shown by the superposed hand-drawn curve in Figure 9.

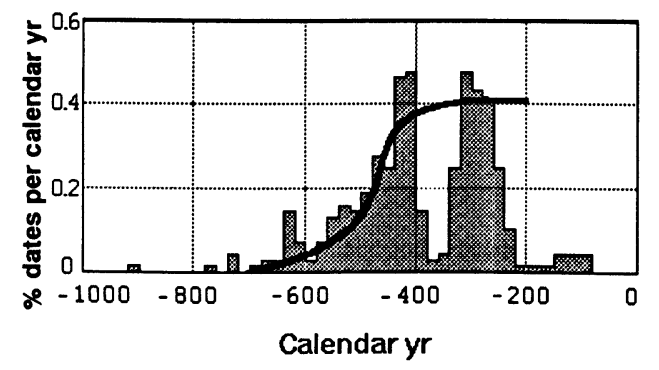

Fig. 9. Likely trend of population growth (-) for New Zealand prehistory, based on ${ }^{14} \mathrm{C}$ dates. The heavy line was drawn by hand to smooth out the variations in the histogram bar heights. 
A settlement date of $c a .700$ cal BP based on the shell distribution agrees with Anderson's (1991) settlement date of ca.700 cal BP based on a selective analysis of dates on charcoal and wood; both are several hundred years later than the generally accepted date of 1000-1200 cal BP (Davidson 1984). The earlier settlement date requires only a small founding population and a reasonable growth rate to reach the population size estimated by the first European explorers (Davidson 1984), whereas the later date requires either an unreasonably high growth rate (Brewis, Molloy and Sutton 1990) or a much larger founding population.

Simmons' (1976) record of Maori oral history alludes to voyages to and from Polynesia and the arrival of many canoes, which is consistent with the archaeological evidence. The discovery of Mayor Island obsidian in early archaeological deposits on Raoul Island in the Kermadec Group, between New Zealand and the Cook Islands (Anderson and McFadgen 1990), strongly supports return voyages to Polynesia. Also, the discovery of a pearl shell fishing lure in an archaeological site at Tairua on the Coromandel Peninsula (Green 1967) in deposits dated several hundred years after first settlement (McFadgen 1994), strongly suggests more than one voyage to New Zealand from Polynesia. Eastern Polynesians 700 yr ago appear to have kept contact between island groups (Irwin 1992), so knowledge of the discovery of New Zealand was probably shared by more than one island group. Early archaeological evidence in New Zealand displays distinct cultural differences between different parts of the country (Davidson 1984), which is consistent with settlement from different parts of eastern Polynesia.

The CSD effect may distort interpretations of events following human settlement of New Zealand. True calendar dates for samples below the minimum turning point of an ambiguous region (Fig. 10A: $a-b)$ are younger than those below the maximum turning point (Fig. 10A: b-c), but have true

A

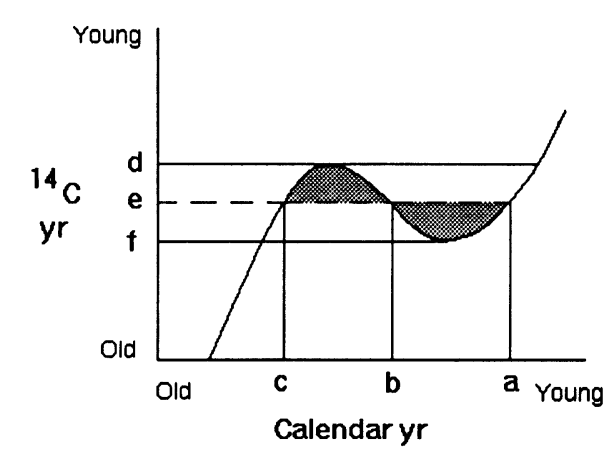

B

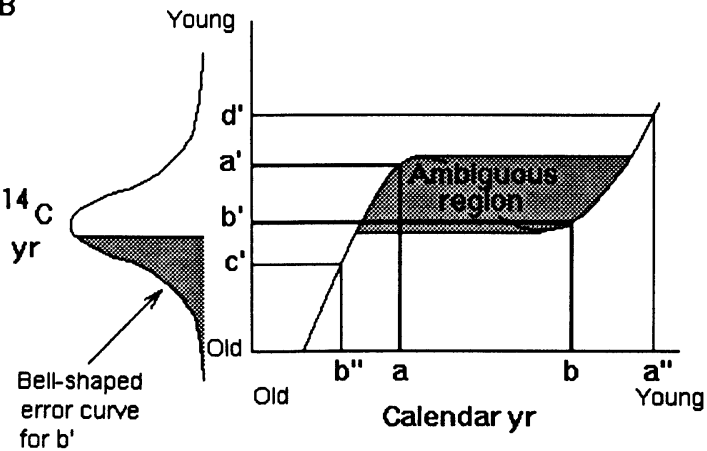

Fig. 10. Diagram showing ${ }^{14} \mathrm{C}$ date reversals caused by ambiguous regions of the calibration curves. A. Two sets of calendar dates $a-b$ and $b-c$ map onto the ${ }^{14} \mathrm{C}$ axis at $e-f$ and $d-e$, respectively. The calendar dates between $a$ and $b$ are younger than those between $b$ and $c$, but have true ${ }^{14} \mathrm{C}$ dates (e-f) that are older than those for $b$ and $c$ (d-e). B. Two individual true calendar dates intercept the calibration curve near the turning points of an ambiguous region. The younger date $b$ is near the minimum, the older date $a$ is near the maximum. Their true ${ }^{14} \mathrm{C}$ dates at $b^{\prime}$ and $a^{\prime}$ are reversed. If $c^{\prime}$ and $d^{\prime}$ are the measured ${ }^{14} \mathrm{C}$ dates for $b^{\prime}$ and $a^{\prime}$, then their calibrated calendar dates are $a^{\prime \prime}$ and $b^{\prime \prime}$, which are reversed and more widely separated than the true calendar dates. 
${ }^{14} \mathrm{C}$ dates that are older (Fig. 10A: e-f ). Measured ${ }^{14} \mathrm{C}$ dates, which are estimates of the true dates, are spread by their counting statistics, in some cases, beyond the boundaries of the ambiguous regions (cf. Fig. 6).

In extreme cases, two events may have measured ${ }^{14} \mathrm{C}$ dates that are not only reversed with respect to their true calendar age, but that also fall outside the boundaries of the ambiguous regions and are significantly different. In Figure $10 \mathrm{~B}$, the probability that the measured ${ }^{14} \mathrm{C}$ date of $\mathrm{b}^{\prime}$ will fall outside the older boundary of the ambiguous region (e.g., at $\left.\mathrm{c}^{\prime}\right)$ is indicated by the shaded part of the bellshaped error curve and is greater than the probability of its falling outside the younger boundary. Similarly, the probability that the measured ${ }^{14} \mathrm{C}$ date of a' will fall outside the younger boundary (e.g., at $\mathrm{d}^{\prime}$ ) is greater than the probability of its falling outside the older boundary. The closer each true ${ }^{14} \mathrm{C}$ age is to the boundary of the ambiguous region, the more likely it is that the measured ${ }^{14} \mathrm{C}$ age will lie beyond the boundary. For true ${ }^{14} \mathrm{C}$ dates lying on their respective boundaries, the maximum probability that both measured dates will lie outside their respective boundaries is 0.25 .

Distortion of this sort produced by the CSD effect may account for young dates on moa bones (Fig. 11) and for old dates on fortifications (Fig. 12). Calibrated dates for moa bones are as young as 300 cal BP, which would be expected if moa hunting stopped at $450 \mathrm{cal} \mathrm{BP}$, shortly after the start of the ambiguous region that occurs between 459 and $312 \mathrm{cal}$ BP on the terrestrial calibration curve. To illustrate this, we assumed that the end of moa hunting was $450 \mathrm{cal} \mathrm{BP}$. We took a uniform sample of calendar dates at 5-yr intervals between 660 and $450 \mathrm{cal}$ BP and their corresponding true ${ }^{14} \mathrm{C}$ dates, and assigned each ${ }^{14} \mathrm{C}$ date a standard error of $67 \mathrm{yr}$ (the average for the moa bone dates). Using the true ${ }^{14} \mathrm{C}$ dates and their assigned standard errors, we generated a simulated set of measured dates. The spread of the calibrated simulated dates matches the spread of the calibrated measured ${ }^{14} \mathrm{C}$ dates (Fig. 11), from which we conclude that the observed moa bone dates could have been generated from samples no younger than $450 \mathrm{cal} \mathrm{BP}$.

To illustrate the distortion of the fortifications' dates, we included dates with inbuilt age; $65{ }^{14} \mathrm{C}$ dates on charcoal and wood are stratigraphically contemporary with some aspect of fort construction or use, and all but 11 have an unknown and possibly large inbuilt age. We excluded dates older than

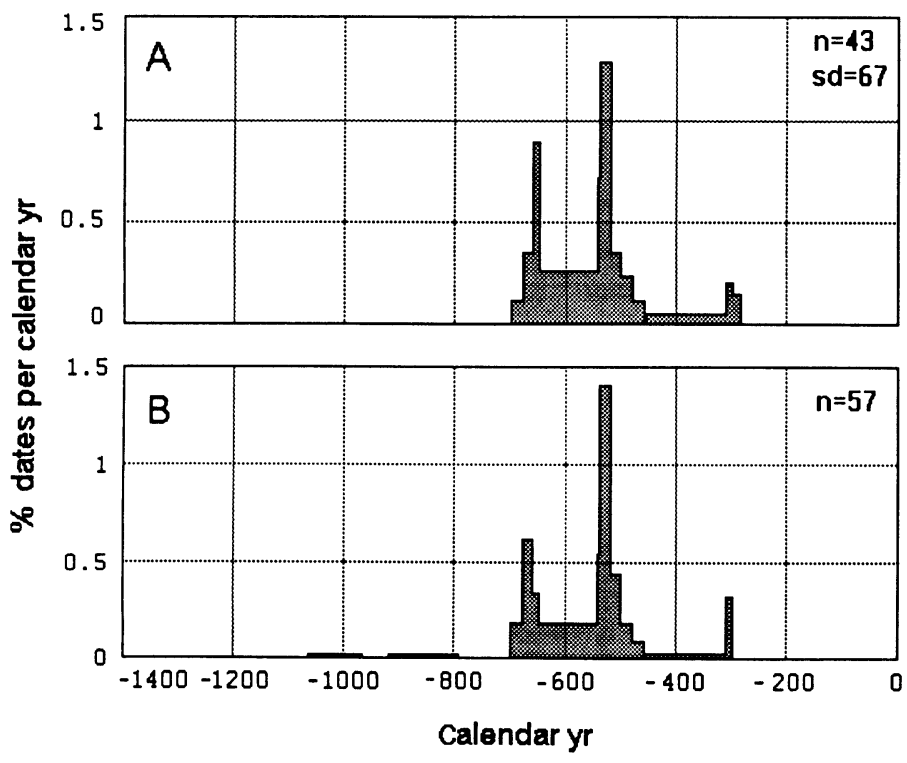

Fig. 11. Calibrated ${ }^{14} \mathrm{C}$ dates on moa bones compared with simulated dates. A. Calendar distribution of a simulated set of ${ }^{14} \mathrm{C}$ dates uniformly distributed at 5 -yr intervals between 660 and $450 \mathrm{cal} \mathrm{BP}$. B. Calendar distribution of calibrated ${ }^{14} \mathrm{C}$ dates on moa bone. We assume the end of simulated moa hunting to be $450 \mathrm{cal} \mathrm{BP}$, just after the start of the ambiguous region of the terrestrial calibration curve, which occurred between 459 and 312 cal BP. The standard error for the simulated moa bone dates (67 $\mathrm{yr}$ ) is the mean value for the measured ${ }^{14} \mathrm{C}$ dates on moa bones. The spread of the calibrated simulated dates closely matches the spread of calibrated measured dates and is explained by the spreading effect of counting errors illustrated by Figure 6 . 
$600 \mathrm{cal}$ BP that have an unknown and possibly large inbuilt age. We took a uniform sample of dates at 2 -yr intervals between 380 and $250 \mathrm{cal} \mathrm{BP}$, and generated a simulated set of measured dates, as described for the moa bone dates, using an assigned standard error of $56 \mathrm{yr}$. The spread of the calibrated simulated dates matches the spread of the calibrated measured ${ }^{14} \mathrm{C}$ dates (Fig. 12), indicating that the observed dates for fortifications could have been generated from samples no older than 380 cal BP.

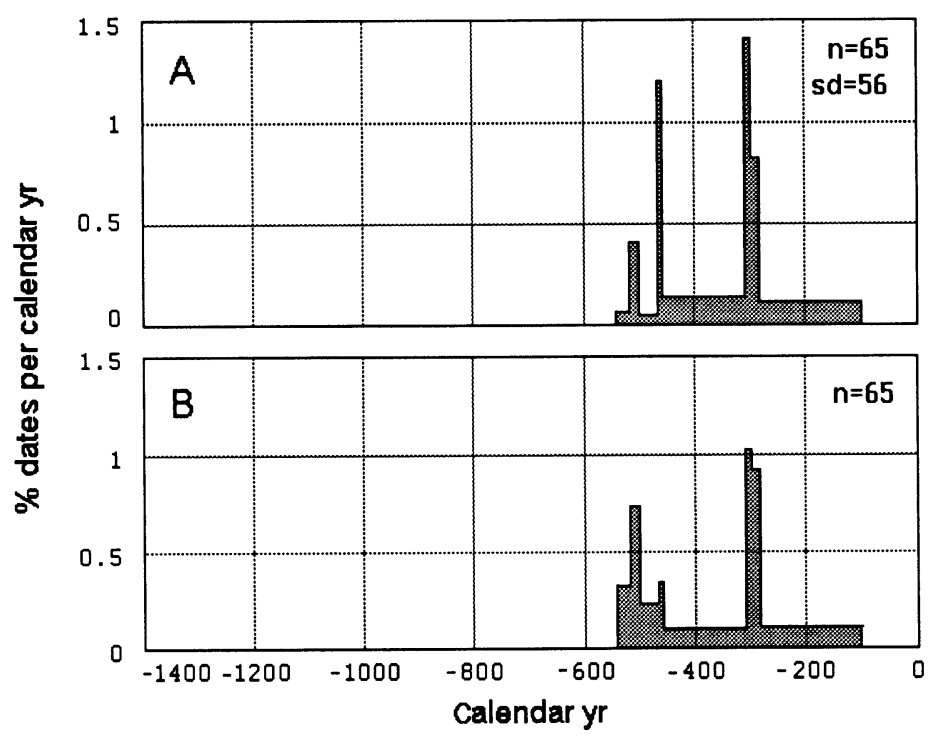

Fig. 12. Calibrated ${ }^{14} \mathrm{C}$ dates on charcoal and wood for fortifications compared with simulated dates. A. Calendar distribution of a simulated set of ${ }^{14} \mathrm{C}$ dates uniformly distributed at 2-yr intervals between 380 and 252 cal BP. B. Calendar distribution of calibrated ${ }^{14} \mathrm{C}$ dates on charcoal and wood from fortifications. We assume the start of simulated fort construction to be $380 \mathrm{cal} \mathrm{BP}$, within the latter part of the ambiguous region of the terrestrial calibration curve (459-312 cal BP). The standard error for the simulated dates $(56 \mathrm{yr})$ is the mean value of the measured ${ }^{14} \mathrm{C}$ dates. The spread of the calibrated simulated dates closely matches the spread of calibrated measured dates and is explained by the spreading effect of counting errors illustrated by Figure 6.

Although there is a gap of $70 \mathrm{yr}$ between the oldest true calendar date for fortifications needed to account for the spread of measured dates and the youngest true calendar date on moa bone needed to account for the spread of measured moa bone dates, the calibrated measured dates overlap by $>200 \mathrm{yr}$. This overlap is caused by the spreading effect of the ambiguous region of the terrestrial calibration curve between 459 and $312 \mathrm{cal} \mathrm{BP}$. The corresponding spread of dates in the marine calibration curve is somewhat less than for charcoal and wood, as illustrated by shell dates for fort construction or use (Fig. 13).

To illustrate the spread of dates on the marine calibration curve, we included measured dates on samples which, although taken from fortifications, may stratigraphically antedate fort construction. Altogether, there are $89{ }^{14} \mathrm{C}$ dates on shells. To simulate these, we took a uniform sample of dates at 2 -yr intervals between 450 and $202 \mathrm{cal} \mathrm{BP}$ and found their corresponding true ${ }^{14} \mathrm{C}$ dates. Using the true ${ }^{14} \mathrm{C}$ dates, we generated a simulated set of measured dates assuming a standard error of $45 \mathrm{yr}$. The spread of the calibrated simulated dates matches the spread of the calibrated measured dates 


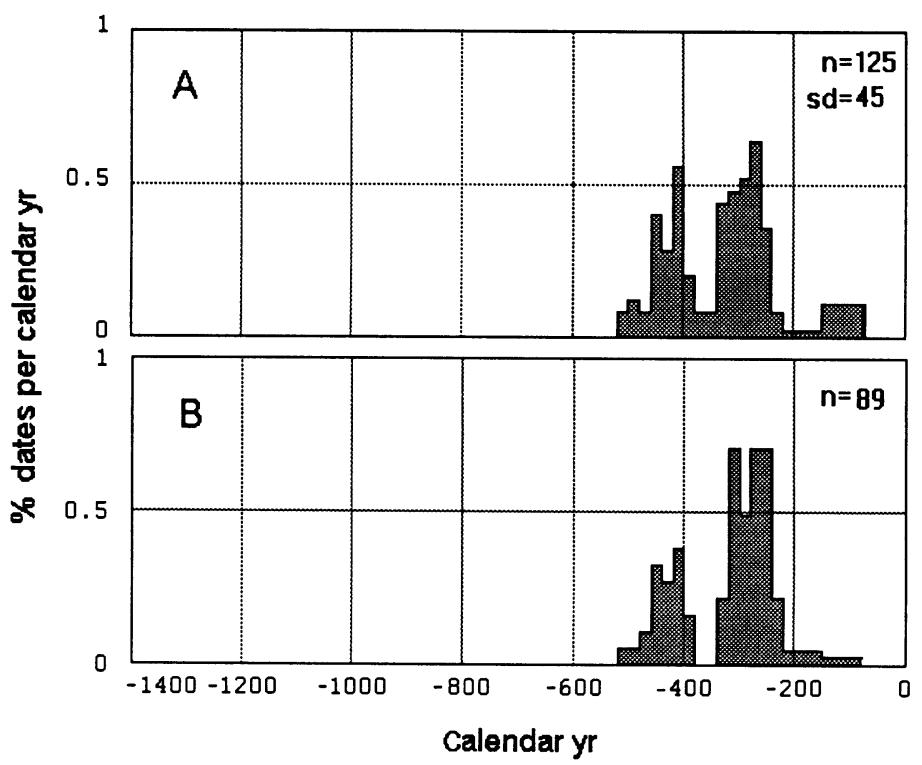

Fig. 13. Calibrated ${ }^{14} \mathrm{C}$ dates on marine shells for Maori fortifications compared with simulated ${ }^{14} \mathrm{C}$ dates. A. Calendar distribution of a simulated set of ${ }^{14} \mathrm{C}$ dates uniformly distributed at 2-yr intervals between 450 and $202 \mathrm{cal}$ BP. B. Calendar distribution of calibrated ${ }^{14} \mathrm{C}$ dates on shells dating occupation of fortifications. We assume the start of simulated fort construction to be $450 \mathrm{cal} \mathrm{BP}$, just before the slope of the marine calibration curve became gentle, and the end to be $202 \mathrm{cal} \mathrm{BP}$. The standard error for the simulated dates $(45 \mathrm{yr})$ is the mean value of the measured ${ }^{14} \mathrm{C}$ dates. The spread of the calibrated simulated dates closely matches the spread of calibrated measured dates and is explained by the spreading effect of counting errors illustrated by Figure 6.

(Fig. 13), indicating that the observed shell dates for fortifications could have been generated from samples no older than $450 \mathrm{cal} \mathrm{BP}$. The difference between the oldest calibrated measured date for forts and the oldest true calendar date necessary to account for the spread of measured dates demonstrates the smaller spread on the marine calibration curve. For marine shell dates, the difference is ca. $70 \mathrm{yr}$; for charcoal and wood dates, $c a .180 \mathrm{yr}$.

Although some of the charcoal and wood samples for dating fortifications have inbuilt ages, and some of the shell samples may be stratigraphically older than defense construction, they indicate that the first appearance of forts is unlikely to be earlier than $450 \mathrm{cal}$ BP, and may possibly be no older than 380 cal BP.

From the above, the first forts appear about the time the inferred trend of population growth (Fig. 9) begins to level off. This suggests an expected scenario: 1) settlement of a new land with abundant resources; 2) population explosion; 3) limitation by resources; and 4) eventual fortification to defend scarce resources.

The true ${ }^{14} \mathrm{C}$ distribution of archaeological dates is that which would be measured if their standard deviations were negligibly small. The observed ${ }^{14} \mathrm{C}$ distribution is the true ${ }^{14} \mathrm{C}$ distribution statistically mixed and spread by convolution with the normal error distribution (i.e., the counting statistics). When the CSD effect is dealt with quantitatively by deconvolving the true ${ }^{14} \mathrm{C}$ distribution from the counting error distribution (a typical standard error for a New Zealand archaeological sam- 
ple is $50 \mathrm{yr}$ ), the estimated date of settlement of New Zealand is likely to become somewhat later than $700 \mathrm{cal} \mathrm{BP}$.

The CSD effect applies to all disciplines that use ${ }^{14} \mathrm{C}$ dates and to all parts of the calibration curve that have wiggles or changes in slope. The effect is apparent in the peaks of the estimated pre-censal population graph for Hawaii that Dye and Komori (1993, Fig. 3) based on an annual frequency distribution for some 600 charcoal dates. These authors are correct to ignore the minor variations of their graph; now that we know the source of the variations, it may be appropriate to rework their data.

The CSD effect is accentuated for older dates because of generally larger standard errors. To obtain accurate distributions of calendar dates, the true ${ }^{14} \mathrm{C}$ distribution is required. One should obtain the true ${ }^{14} \mathrm{C}$ distribution from the observed ${ }^{14} \mathrm{C}$ distribution by deconvolution from the counting error distribution, which reduces the spread of ${ }^{14} \mathrm{C}$ dates and, when mapped through the calibration curve, evens out the troughs and peaks and shortens the tail of the calendar distributions. This applies whether the dates are archaeological, geological or the basis for the calibration curve itself. One can then obtain the true calendar distribution of dates from the true ${ }^{14} \mathrm{C}$ distribution by using the calibration curve in the normal way. The CSD effect is present any time a non-linear transformation, combined with significant statistical spreading of observed data, is used to predict the value of a second variable. This is not necessarily restricted to ${ }^{14} \mathrm{C}$ dating.

\section{ConClusions}

1. Inbuilt ages of old wood used for fires and sampled for ${ }^{14} \mathrm{C}$ dating add to the distribution of archaeological dates a "tail", which may extend for several hundred years before the event being dated.

2. After excluding charcoal and wood likely to have inbuilt ages, the date of settlement of New Zealand indicated by dates on charcoal and wood is close to that indicated by dates on shells: ca. $700 \mathrm{cal} \mathrm{BP.}$

3. The shape of the distribution of calibrated ${ }^{14} \mathrm{C}$ dates is distorted by a CSD effect and displays spurious peaks and troughs, which are more extreme in the distribution of charcoal and wood dates than in the distribution of shell dates. After allowing for the CSD effect, we infer from the shell dates that the prehistoric population in New Zealand grew to a maximum $c a .400 \mathrm{cal} \mathrm{BP}$ and then leveled off.

4. The CSD effect increases the spread of calendar dates, enhances the possibility of date reversals, and causes some dates for events occurring within ambiguous regions to fall outside these regions. In general, the spread of dates on shells is less than the spread of dates on charcoal and wood. After taking the CSD effect into account, the first appearance of fortifications indicated by shell dates is unlikely to have been earlier than $450 \mathrm{cal} \mathrm{BP}$, and as indicated by charcoal and wood dates, may have been no earlier than $380 \mathrm{cal} \mathrm{BP}$.

5. The effects described in this paper show that many dates for an event are preferable to few dates, and where possible dates on both terrestrial and marine samples should be obtained. We are undertaking further research to reduce the spreading caused by the CSD effect and to refine the calibration of ${ }^{14} \mathrm{C}$ dates.

\section{ACKNOWLEDGMENTS}

We thank Mr. Brian Sheppard, Science Manager, Science and Research Division, Department of Conservation, Wellington, for his outspoken support of the research covered in this paper. We are also grateful to Dr. Rodger Sparks, Rafter Radiocarbon Laboratory, Lower Hutt, for granting us access to the laboratory ${ }^{14} \mathrm{C}$ database, and for useful discussion of the matters covered in this paper. 


\section{REFERENCES}

Anderson, A. J. 1991 The chronology of colonisation in New Zealand. Antiquity 65: 767-795.

Anderson, A. J. and McFadgen, B. G. 1990 Prehistoric two-way voyaging between New Zealand and East Polynesia: Mayor Island obsidian on Raoul Island, and possible Raoul Island obsidian in New Zealand. Archaeology in Oceania 25: 24-37.

Bird, C. F. M. and Frankel, D. 1991 Chronology and explanation in western Victoria and south-east South Australia. Archaeology in Oceania 26: 1-16.

Brewis, A. A., Molloy, M. A. and Sutton, D. G. 1990 Modelling the prehistoric Maori population. American Journal of Physical Anthropology 81: 343-356.

Davidson, J. M. 1984 The Prehistory of New Zealand. Auckland, Longman Paul: 270 p.

Dye, T. and Komori, E. 1993 A pre-censal population history of Hawaii. New Zealand Journal of Archaeology 14: 113-128.

Geyh, M. A. 1980 Holocene sea-level history: Case study of the statistical evaluation of ${ }^{14} \mathrm{C}$ dates. In Stuiver, M. and $\mathrm{Kra}$, R. S., eds, Proceedings of the 10th International ${ }^{14} \mathrm{C}$ conference. Radiocarbon 22(3): 695-704.

Green, R. C. 1967 Sources of New Zealand's East Polynesian culture: The evidence of a pearl shell lure shank. Archaeology and Physical Anthropology in Oceania 2: 81-90.

Irwin, G. 1992 The Prehistoric Exploration and Colonisation of the Pacific. Cambridge, Cambridge University Press: $240 \mathrm{p}$.

McFadgen, B. G. 1982 Dating New Zealand archaeology by radiocarbon. New Zealand Journal of Science 25: 379-392.

1994 Coastal stratigraphic evidence for human settlement. In Sutton, D. G., ed., The Origins of the First New Zealanders. Auckland, Auckland University Press: 195-207.

McFadgen, B. G. and Manning, M. R. 1990 Calibrating New Zealand radiocarbon dates of marine shells.
Radiocarbon 32(2): 229-232.

Richards, T. H. and Rousseau, M. K. 1987 Late Prehistoric Cultural Horizons on the Canadian Plateau. Department of Archaeology Simon Fraser University Publication 16: $102 \mathrm{p}$.

Simmons, D. R. 1976 The Great New Zealand Myth: A Study of the Discovery and Origin Traditions of the Maori. Wellington, Reed: 504 p.

Snedecor, G. W. and Cochran, W. G. 1967 Statistical Methods. Ames, The Iowa State University Press: 593 p.

Stolk, A., Hogervorst, K. and Berendsen, H. 1989 Correcting ${ }^{14} \mathrm{C}$ histograms for the non-linearity of the radiocarbon time scale. Radiocarbon 31(2): 169-178.

Stuiver, M. and Braziunas, T. F. 1993 Modeling atmospheric ${ }^{14} \mathrm{C}$ influences and ${ }^{14} \mathrm{C}$ ages of marine samples to 10,000 BC. In Stuiver, M., Long, A. and Kra, R. S., eds., Calibration 1993. Radiocarbon 35(1): 137-189.

Stuiver, M. and Pearson, G. W. 1993 High-precision bidecadal calibration of the radiocarbon time scale, $\mathrm{AD}$ 1950-500 BC and 2500-6000 BC. In Stuiver, M., Long, A. and Kra, R. S., eds., Calibration 1993. Radiocarbon 35(1): 1-23.

Stuiver, M. and Polach, H. 1977 Discussion: Reporting of ${ }^{14} \mathrm{C}$ data. Radiocarbon 19(3): 355-363.

Stuiver, M. and Reimer, P. J. 1989 Histograms obtained from computerized radiocarbon age calibration. In Long, A., Kra., R. S. and Srdoð, D., eds, Proceedings of the 13th International ${ }^{14} \mathrm{C}$ Conference. Radiocarbon 31(3): 817-823.

Stuiver, M. and Reimer, P. J. 1993 Extended ${ }^{14} \mathrm{C}$ data base and revised CALIB $3.0{ }^{14} \mathrm{C}$ age calibration program. In Stuiver, M., Long, A. and Kra, R. S., eds., Calibration 1993. Radiocarbon 35(1): 215-229.

Vogel, J. C., Fuls, A., Visser, E. and Becker, B. 1993 Pretoria calibration curve for short-lived samples, 19303350 BC. In Stuiver, M., Long, A. and Kra, R. S., eds., Calibration 1993. Radiocarbon 35(1): 73-85. 